The rats of a third group each received subcutaneously on seven successive days $1 \mathrm{mgm}$. of 'vitamin A-acid' dissolved in 0.2 c.c. of the same buffer. On the ninth day the vitamin A content of the livers was zero.

The rats of a fourth group received orally on three successive days $3 \mathrm{mgm}$. of vitamin A-acid as sodium salt dissolved in 0.3 c.c. phosphate buffer $p H$ 10.5. On the fifth day the vitamin A content of the livers proved to be zero.

From the above experiments we may conclude that the sodium salt of vitamin A-acid, whether administered orally or subcutaneously, is not converted into vitamin $\mathbf{A}$, and probably itself exerts its biological activity.

Laboratory of N. V. Organon,

$$
\begin{aligned}
& \text { J. F. ARens } \\
& \text { D. A. VAN DorP }
\end{aligned}
$$

Oss, Holland.

Aug. 23. .

Nature, 157, 190 (1946) ; 158, 60 (1946). Rer. Trav, Chim., 65, 338 $(1946)$.

\section{Use of Water Purified by Synthetic Resin Ion-Exchange Methods for the Study of Mineral Deficiencies in Plants}

As adequate supply of highly purified water is an essential requirement for the study of plant nutrition problems, particularly those relating to mineral deficiencies, when experiments are carried out on a large scale. Liebig, Vanselow and Chapman ${ }^{1}$ in California found that tap water purified by the synthetic resin ion-exchange principle was satisfactory for maintaining healthy growth in citrus and sweet lemon without any toxic effects. They did not, however, report any experiments using demineralized water in deficiency cultures, although they published analytical results indicating that considerable removal of certain of the major and trace elements was effected by the treatment. Schroeder, Davis and Schafer ${ }^{2}$ have recently published a note in which they conclude that demineralized tap water is unsuitable as a substitute for distilled water for boron-deficiency cultures. Using the latter, symptoms of this deficiency developed in canning beet in five weeks, whereas, in parallel cultures with the demineralized water, no symptoms were observed.

I have previously reported ${ }^{3}$ the use of demineralized water at Long Ashton, using the 'Permutit' method, for large-scale sand culture work, using both a hard tap water and rain water, but in view of the unfavourable results obtained for boron by Schroeder et al., it is of interest to refer to results obtained at Long Ashton for both boron and other nutrient elements.

In deficiency experiments with plants, the ultimate test of any point of technique must be that of biological analysis, and using such a criterion a number of indicator crops have been grown under deficiency conditions to test a demineralizing apparatus during the 1945 and 1946 seasons. The effectiveness of the technique was judged by the method of visual diagnosis, and the purity of the treated water was also checked by chemical analysis.

Using tap water, the following deficiencies were produced in acute forms : nitrogen, phosphorus, calcium, magnesium, potassium and manganese in tomato (Market King); calcium in sugar beet and hungry gap kale; iron in oats (Star); boron in cauliflower (Majestic), sugar beet and celery.

Using rain water, in extensive experiments with a large variety of crops, the following deficiencies were observed : iron in tomato, potato, sugar beet, red clover, marrowstem kale, flax, wheat, oats; manganese in tomato and globe beet; boron in tomato, potato, sugar beet, globe beet, red and alsike clover, lucerne, dwarf, broad and runner bean, pea, flax, parsnip. The severity of calcium deficiency symptoms, in crops like alsike clover, parsnip, flax and cereals, was greatly accentuated over that produced by the use of untreated rain water.

The effectiveness of the removal of specific inorganic ions depends on the total concentration of other ions present; for example, efficiency of removal of a small quantity of iron increases as the amounts of calcium and magnesium decrease. Considerable increase in efficiency, and improvement in $p \mathrm{H}$ reaction and sodium elimination has been obtained by the use of a secondary cation exchanger to reduce further the cation level in the water, although the anion content is not changed.

The analytical results of Liebig et al. do not show appreciable reduction in boron content, and experience at Long Ashton shows that boron is less readily removed than some ions; but with rain water having an initial boron content of about 0.01 p.p.m., the boron level can be reduced to as little as 0.0025 p.p.m.

The apparatus in use at present has delivered more than 1,000 gallons of purified rain water without regeneration, and the figures for iron content are representative of its efficiency: April storage rain water 0.03 p.p.m., purified 0.0017 p.p.m. ; August storage rain water 0.50 p.p.m., purified 0.003 p.p.m.

The use of demineralized water holds considerable possibilities for large-scale trace element research, and further experiments in this direction are in progress. Full details of technique and analyses will be published later.

This work has been carried out under the Agricultural Research Council's scheme for plant nutrition with the aid of special grants for which grateful acknowledgment is made. I wish to thank the Permutit Co., London, for their interest and helpful co-operation in the design of suitable equipment and for making the apparatus available for use in the experimental sand cultures at Long Ashton.

Research Station,

Long Ashton,

Bristol.

Sept. 16.

${ }^{1}$ Liebig, G. F., jun., Vanselow, A. P., and Chapman, H. D., Soil Science, 55, 371' (1943).

${ }^{2}$ Schroeder, W. T., Davis, J. F., and Schafer, J., jun., J. Amer. Soc. Agron., 38, 754 (1946).

${ }^{3}$ Hewitt, E. J., Long Ashton Res, Stn. Ann. Rep. (1945), 44.

\section{Adsorption on Carbon of Rare Earth Organic Complexes}

Although Botti ${ }^{1}$ studied the adsorption on activated carbon of members of the rare earth group, and Croatta ${ }^{2}$ and others ${ }^{3}$ have examined chromatographical methods of their separation, the investigations of these workers have been confined to rare earth ions as such. 